The 49th Annual Conference of the International Association of School Librarianship

The 24th International Forum on Research on School Librarianship

July $12-16,2021$

Oksana Zavalina

University of North Texas

oksana.zavalina@unt.edu

\title{
Notes Fields in Metadata Records Generated by the Children's and Young Adults' Cataloguing Program: Exploration of Support for General Specific Needs of School
}

\author{
Library Users
}

\begin{abstract}
Notes fields in metadata records used in school library catalogs provide important value added and facilitate resource discovery for students and teachers. Variety of notes are intended to support general user tasks, as well as specific user tasks of school library users. The study reported in this paper examined levels and patterns of application of summary notes, audience notes, grade level notes, reading interest level notes, study program information notes, table of contents notes etc. in the bibliographic records created by the United States Library of Congress Children's and Young Adults' Cataloguing Program for fiction books between 2014 and 2020.
\end{abstract}

Keywords: Metadata, notes fields, CYAC, school library

\section{Introduction and Concise Review of Relevant Literature}

Bibliographic records that represent resources for children and young adults are important in providing access to these materials for school library users: students, teachers, etc. These records are normally generated through a collaboration of publishers and cataloging agencies. For example, the Children's and Young Adults' Cataloging (CYAC) Program has functioned at the United States Library of Congress for over 50 years since the 1960s, when it was called the Annotated Card (AC) Program. The CYAC program has been working through Cataloging-In-Publication (CIP) program to provide bibliographic record creation and augmentation services for school and public libraries: first in analog form for card catalogs, later in the form of electronic records for online catalogs (Library of Congress, 2021). The program covers all children's or young adult fiction works published in any language in the United States and received through the CIP Program or the US Library of Congress Copyright Office.

As part of ensuring that bibliographic records support general user tasks of finding, identifying, selecting, obtaining, and exploring information as defined in models and guidance documents for bibliographic metadata such as for example the Library Reference Model (IFLA, 2017), CYAC program commits to providing brief informative notes summarizing the content of juvenile materials as well as other notes of importance to users of school libraries (e.g., intended audience 
notes, etc.) (Library of Congress, 2012, 2015). Summary notes are considered useful to users of school libraries: both adults and children (Weihs \& Intner, 2017, etc.). In addition to summary notes, CYAC Program assigns children's subject and genre headings. The overall process of creating CYAC record for as CIP work of fiction is quite time-consuming. The US Programs, Law ands Literature Division of the US Library of Congress expanded support for the CYAC program in 2019 which resulted in faster turnaround times that reduced from 55 days to 26.2 days per CYAC CIP title. As of 2019, CYAC program processed approximately 3500 bibliographic records a year (IFLA, 2019). More recent statistics on CYAC program record production has not been made available yet but according to US Library of Congress report at the annual meeting of the International Federation of Library Associations and Institutions, the overall production of the CIP program, of which CYAC is part, remained at nearly pre-pandemic level in 2020 when cataloging workflows had to change drastically to accommodate teleworking (IFLA, 2020).

The value of the kinds of information that are traditionally emphasized in the CYAC-produced metadata records for the users of children's materials has been confirmed by research. For example, Beak's study (2012) identified 15 groups of factors affecting children's selection of books. Beak found that these factors include table of contents and summary or review from back of books (grouped by researcher in the "Content / Stories" facet). In addition, Beak's "Difficulty, reading level, understandability" facet includes such information as age appropriateness, along with some other factors. Based on these findings, researcher's recommendation was to consider these children; s book selection factors in metadata creation for school library catalogs by providing table of contents, summary, age level, etc. notes.

CYAC program seeks advise and feedback on cataloging needs from professional organizations such as for example American Library Association (ALA) and its Association for Library Collections and Technical Services (ALCTS) division that traditionally focuses on cataloging and classification guidelines and has recently become part of the Core: Leadership, Infrastructure, Futures organization. CYAC-produced metadata records are contributed to the United States Library of Congress online catalog, as well as to centralized bibliographic databases. The largest and most well-known globally centralized bibliographic database is WorldCat https://www.worldcat.org/ managed by the Online Computing Library Center (OCLC). Bibliographic records created by various programs at the US Library of Congress tend to follow high quality standards and are often preferred as a source of copy cataloging over records contributed to WorldCat by other members of OCLC cooperative cataloging (Thomas, 1996, etc.). Records created as part of the CIP program (including those contributed by CYAC program) are normally based on pre-publication galleys provided by publishers. For this reason, these records tend to be changed significantly after publication of the works represented by them (Taylor \& Simpson, 1986, etc.). As part of WorldCat metadata management, OCLC staff enrich master records with additional layers of metadata considered important for information access: 
among other enrichment this includes adding of tables of contents, etc. (OCLC, 2009). OCLC member institutions worldwide import copies of WorldCat records to their online catalogs, and often augment master records to better meet the needs of their users.

\section{Research Problem Statement}

The CYAC program operated by the United States Library of Congress plays an important role as a contributor of bibliographic records used in school library catalogs. Records contributed by the CIP program as a whole have been carefully analyzed, including examination of notes fields (e.g., by Taylor \& Simpson, 1986). However, these examinations were performed decades ago, and there are no recent analyses published. Moreover, results of analysis of CYAC-originated records have not been included in any publications so far. In particular, there is a lack of studies focusing on the notes metadata fields that support both general and specific needs of school library users: summaries, reading grade level, interest age level, motivation/interest level, other audience characteristics, study program information notes, etc. The study reported in this paper attempts to begin bridging this gap by addressing the following research question: What are the levels and patterns of application of notes fields of interest for school library users in recently created by CYAC WorldCat bibliographic records representing juvenile fiction works?

\section{Study Methods}

A total of 688 unique WorldCat metadata records created over the period of 2014-2020 by the CYAC program to represent fiction works in book form were identified and collected using MarcEdit in January of 2021. Manual and partially automated content analyses were applied to collected records. This included evaluation of levels and patterns of application of data elements that are emphasized by the CYAC cataloging guidelines: summary notes (MARC 21 field 520) and different types of target audience notes -- reading grade level, interest age level, motivation/interest level, etc. -- recorded in MARC 21 field 521. Application of other data elements that contain information important for supporting the general and specialized needs of school library users were also analyzed. This included the recently added audience characteristics field 385 , the traditionally widely used in various library settings general notes field (500), the table of contents note (field 505) that is generally considered an added value in metadata records, as well as study program information notes (field 526), and other relevant fields. The findings are reported below.

\section{Findings and Discussion}

The number of "holdings" -- OCLC member institutions that had the book represented by record in their collection and has the records in their catalogs ranged between 1 and 3795 . The average number of institutions holding the item and the record was slightly over 271 and the median was 87.5. 
Most of the records were found to contain one or more types of notes. The level of application of these fields are presented in Figure 1.

\section{Figure 1}

Levels of application of MARC 21 notes fields $5 X X$ and field 385 Audience Characteristics observed in a dataset of WorldCat records created by CYAC program in 2014-2020 (n=688)

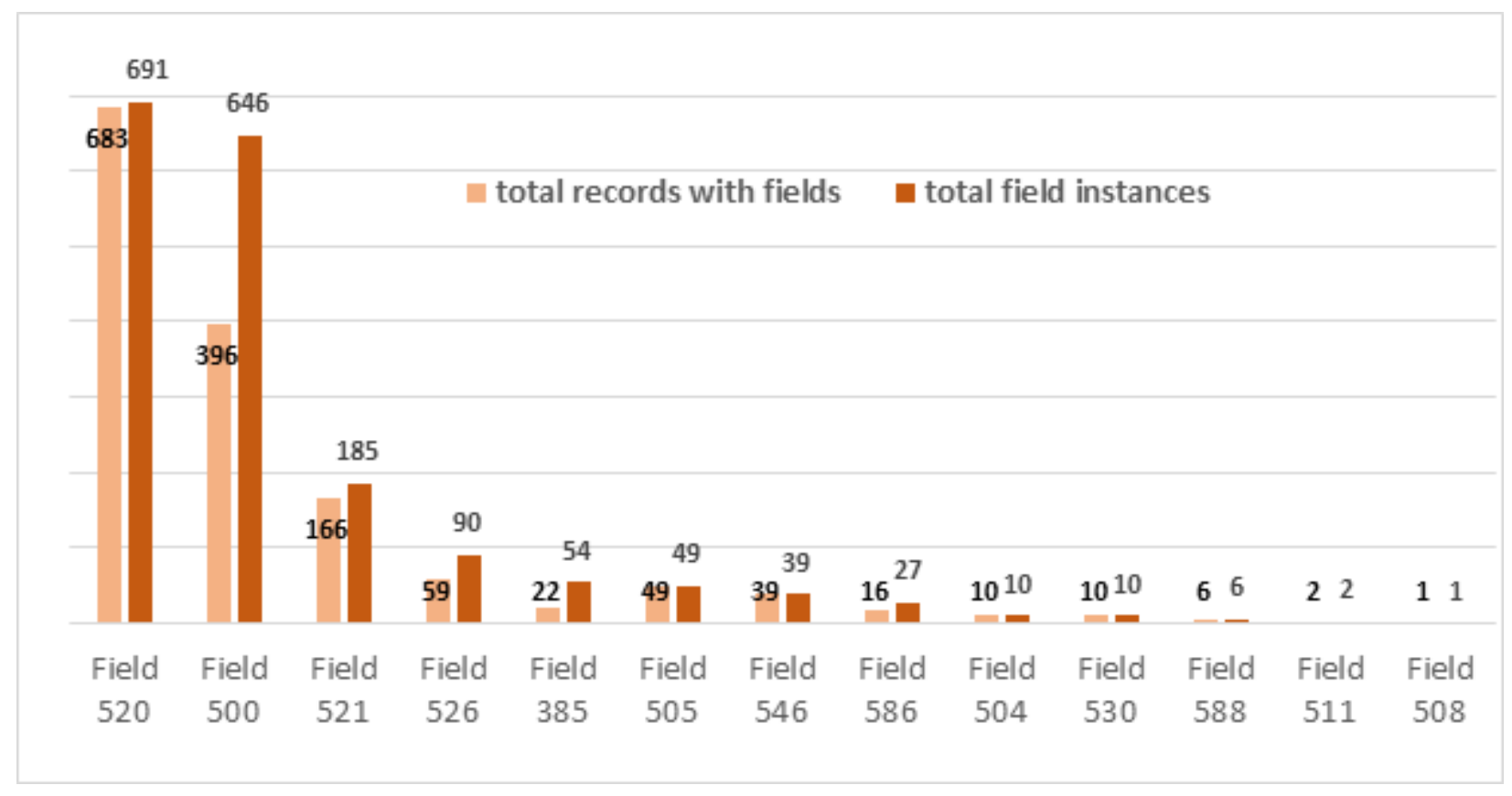

Summary notes that are emphasized in the CYAC program cataloging were included in fields 520 in over $99 \%$ of analyzed records. Field 520 appeared in a total of 691 instances which brings the average number of instances per record to 1.0117 as several record included 2 or 3 instances. Interestingly, $1 \%$ of records included 2 to 3 instances of identical summary notes. The average length of a data value in a summary field was 36.86 words, with a median of 28 , and a standard deviation of 31.48. The observed average length is consistent with the CYAC guidelines for writing summary notes that suggest 25-30 words length but also include flexibility provisions (Library of Congress, 2012). However, lengths of summaries were found to range widely from as little as 5 words to 297 words, or 10-times the CYAC-recommended length (see Table 1). The longest summary note field was found in the record with the higher than average number of holding institutions: 544. That record was edited a total of 48 times in the almost 5 years between the date of its creation and the date of data collection for this study, so it is unclear if the length of the summary is a result of edits made by holding institutions. 
Table 1

The shortest, average-length, and the longest summary notes

\begin{tabular}{|c|c|c|}
\hline $\begin{array}{l}\text { Shortest data } \\
\text { value in field } \\
520 \text { Summary } \\
\text { note: } 5 \text { words }\end{array}$ & $\begin{array}{c}\text { Example of an } \\
\text { average-length data } \\
\text { value in field } 520 \\
\text { Summary note: } 37 \\
\text { words }\end{array}$ & Longest data value in field 520 Summary Note: 297 words \\
\hline $\begin{array}{c}\text { Illustrations } \\
\text { accompany } \\
\text { rhyming word } \\
\text { play. }\end{array}$ & $\begin{array}{l}\text { In } 2353 \text {, as the } \\
\text { Ultraball games ratchet } \\
\text { up in intensity, with } \\
\text { teams using explosive } \\
\text { hew tactics to reach the } \\
\text { Ultrabowl, Strike has } \\
\text { bigger decisions to } \\
\text { make if he wants to } \\
\text { keep his } \\
\text { teammates--and the } \\
\text { moon--safe. }\end{array}$ & $\begin{array}{l}\text { Becket is an ordinary teenage girl, wrestling with the upheaval } \\
\text { of her parents' divorce. A studious high school senior, her } \\
\text { biggest problems to date have been choosing which colleges to } \\
\text { pply to, living up to her parents' ambitious expectations for her, } \\
\text { and fighting her secret crush on her best friend's boyfriend. But } \\
\text { that all changes on the night she tries to save an innocent life } \\
\text { and everything goes horribly wrong. Unbeknownst to her, } \\
\text { Becket has been tricked into opening a door between worlds, } \\
\text { allowing a dark magic into the mortal world. As the magic } \\
\text { trickles in, the city begins to change at night. Strange creatures } \\
\text { oam the streets, and inanimate objects come to life, all of them } \\
\text { bloodthirsty and terrifying. The city returns to normal when the } \\
\text { sun rises in the morning, and no one can capture the strange } \\
\text { changes -- such as potholes turning into toothy mouths and } \\
\text { vires turning into strangling vines -- on film, which prompts the } \\
\text { government to declare that the city has been infected with some } \\
\text { kind of madness and must be quarantined. Meanwhile, } \\
\text { venturing out of one's house at night has become a dangerous } \\
\text { proposition, and the moment the sun sets, most of the citizens of } \\
\text { the city shut themselves up in their houses and stay there even } \\
\text { in the case of dire emergencies. The magic is openly hostile to } \\
\text { most mortals, but there are some individuals it seems to covet, } \\
\text { rying to lure them out into the night. While Becket struggles to } \\
\text { protect her friends and family from predatory creatures of the } \\
\text { night, she is constantly tempted to shrug off all her } \\
\text { responsibilities and join them. Joining the night world means } \\
\text { being free of not just responsibility, but conscience, and it } \\
\text { means no longer caring about the fate of others. }\end{array}$ \\
\hline
\end{tabular}


The level of application of target audience notes (MARC 21 field 521) was much less consistent than that of a summary note field 520: $24.13 \%$ of records in the dataset. Seventeen records had 2 instances of field 521, one record had 3 instances, and the remaining 148 records included a single instance of field 521. In a total of 16 instances, the source of data in the target audience note was specified: in 4 cases, this was the name of the publisher ("Harper", "Stone Arch Books"), and in the remaining 11 cases, the source was specified as Lexile.

Based on the "display constant controller" encoded in the first indicator of the MARC 21 field 521 target audience note (https://www.loc.gov/marc/bibliographic/bd521.html), the only variety of the target audience note not represented in the analyzed dataset was motivation/interest level note. Other 6 kinds of target audience notes were observed in between 5 and 119 instances each. The unspecified (general) audience note was used in $10.8 \%$ of records. A variety of levels of specificity was observed in the data values, including but not limited to age ranges (e.g., "Middle Grade Fiction", "For ages: 12+ years old", "Guided Reading Level: M", "For children"). Almost two-thirds of instances (64\%) of fields were coded as representing interest age level. This most often included simple concise age range statements (e.g., "Ages 4-8"). A low proportion of instances of interest age level notes had numeric-only age data entered in a standardized 3-character-long way with leading zeros (e.g., "006-008", "012+"). Likewise, the small proportion of interest age levels included somewhat longer statements such as "Suitable for $0+$ " or "Appeals to 2nd-3rd graders" which based on MARC 21 guidelines should have been coded as an interest grade level note.

Target audience notes were coded as interest grade level in 3.8\% of field 521 instances observed in the dataset, and in most cases included the phrase "Appeals to" and the word "graders". One instance of a field coded as interest grade level note included numeric-only data value representing a range with two 2-character-long numbers: "04-07". One additional instance included an unclear data value "P-P" which might possibly indicate "Preschool", but such an abbreviated data value would have been confusing for users of school library catalogs.

Reading grade level note variety of the field 521 target audience note was observed in $5.4 \%$ of records (e.g., "Kindergarten - 3", "Reading level grade 4"). Special audience characteristics information was included in only $2.7 \%$ of field 521 instances. All instances included the Lexile Framework for Reading (https://lexile.com/) controlled-vocabulary terms for Decoding, Patterns, Sentences, Sentence length, and/or Vocabulary, with varying level of detail provided, e.g.:

- $52131 \$$ aSentence length: 1 (very easy)\$bLexile

- 521 31\$aDecoding: 3 (medium)\$aVocabulary: 4 (hard)\$aSentences: 5 (very hard)\$aPatterns: 5 (very hard)\$blexile.

Lexile was also the controlled vocabulary used as a source of data values in 6 instances of target audience note without display constant generated, as evidenced by MARC 21 1st field indicator 
8 (e.g., $52181 \$ a G N 320 \mathrm{~L} \$ b L$ exile). In two records representing pop-up books, target audience notes with no constant display generated provided a choking hazard warning.

A total of 54 instances of field 385 Audience Characteristics were observed in $22(3.05 \%)$ records. Field 385 is an additional field, beyond 521, to represent audience information, and it is intended to rely on terms and/or codes from controlled vocabularies such as for example, MESH, LCSH, ERIC, etc. to represent the intended categories of persons (including demographic categories) and intellectual level for which the resource content is appropriate. Although fields 385 and 521 are considered complementary, only in 9 records out of 22 containing field 385 (40.91\%), this field co-existed with field 521. Educational level group was represented in 30 instances of field 385 total in 5 records. The rest of the instances represented the age group. All but two records relied on the same controlled vocabulary in field 385: US Library of Congress Demographic Group Terms

(LCDGT) https://www.loc.gov/aba/publications/FreeLCDGT/freelcdgt.html which might or might not be an indication that these fields and their data values were added by the CYAC Program catalogers. Two additional records used German-language terms from the Integrated Authority File" (Gemeinsame Normdatei, GND) of the German National Library (DNB). Field 385 is not one of the metadata fields traditionally emphasized by the CYAC program. Also, it was added to the MARC 21 Bibliographic Format standard relatively recently, in 2013 which could be one of the reasons of generally lower level of this field utilization among catalogers of OCLC-member institutions who adapted CYAC-created records for their databases.

Study program information (field 526) notes were found in 90 records $(8.68 \%$ of the analyzed dataset), with 1.1867 instances on average per record with the field. Over $83 \%$ of the study program information notes represented the reading program as indicated by the 1 st indicator 0 in this MARC 21 field: https://www.loc.gov/marc/bibliographic/bd526.html. Based on the similarities of data values between instances of this field with 1 st indicator 0 and instances with 1st indicator 8 (which stands for no display constant generated), the remaining $17 \%$ of field 526 instances are also intended by catalogers adding them to represent reading programs.

Almost $86 \%$ of all instances of field 526 - regardless of the $1^{\text {st }}$ indicator -- were found to represent the Accelerated Reader reading incentive program and curriculum assessment tool: mostly encoded in program name subfield simply by its name, and occasionally (6 instances) in combination with Renaissance Learning -- the name of producer of this program and tool. Remaining $17 \%$ of instances of field 526 observed in the dataset were used to represent the Scholastic Lexile-based Reading Counts reading program. Unlike with Accelerated Reader program, this program was entered in subfield $\$ a$ of fields 526 simply by its name "Reading Counts", without the publisher's name. In addition to subfield \$a which holds the reading program name, most instances of field 526 included subfields \$c reading level (e.g., "5.1", "6.4", etc.), \$d title point value (e.g., "11.0", “0.5”), \$b interest level (e.g., "3-5", "Lower grades", 
"High school”, "LG", "MG”, "UG” etc.), and \$z public note pertaining to the study program (in most cases a numeric-only 6-character-long data value such as "128716" and occasionally a more informative data value such as "quiz: 110477”). MARC 21 field 526 supports a very important specialized user task of teachers and school librarians in selecting appropriate reading materials to improve students' reading skills. To facilitate reading development, it should be included whenever applicable.

\section{Figure 2}

Example of a CYAC-contributed WorldCat MARC 21 record with multiple notes fields

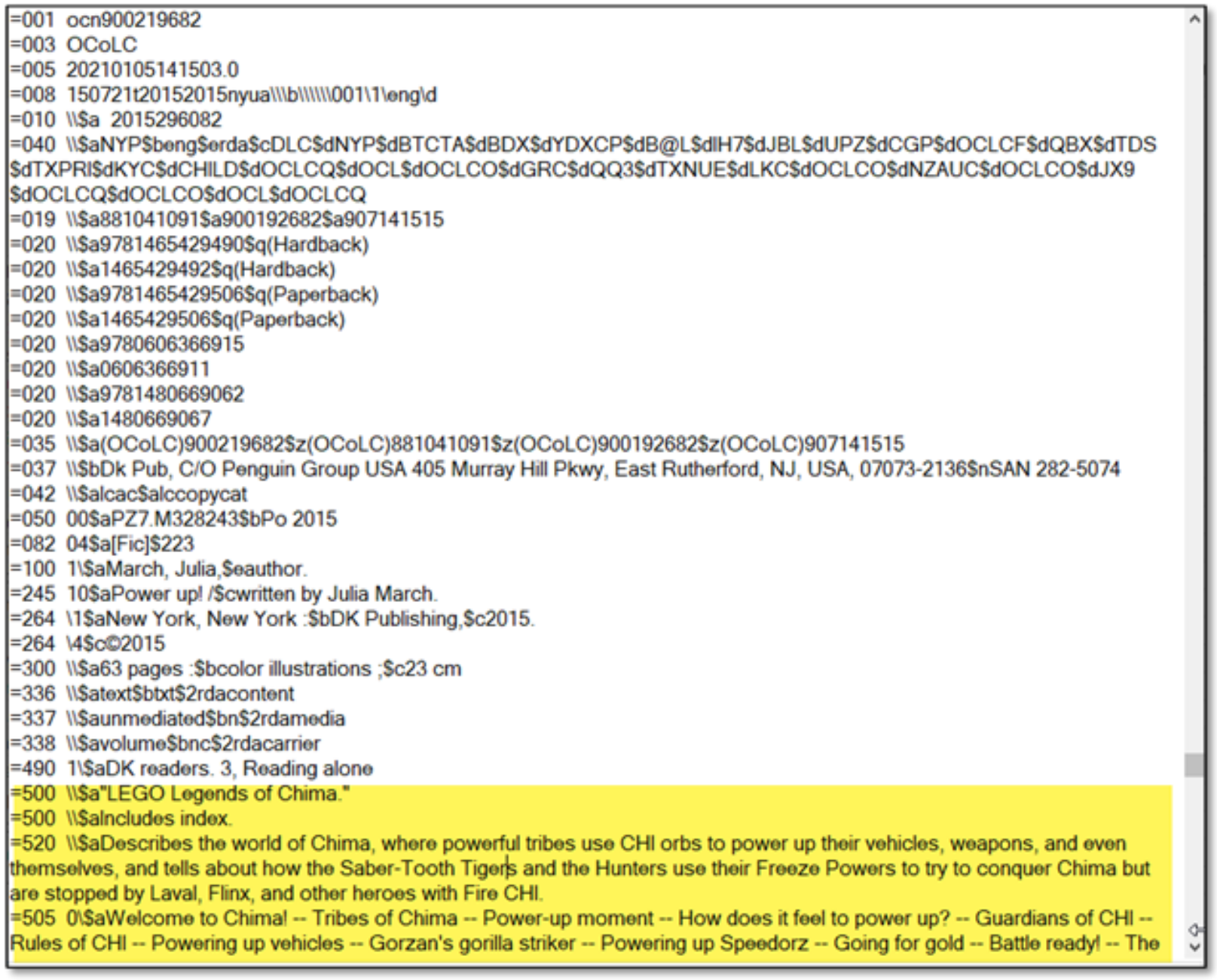

Two or more notes fields were found to often appear together within a record. Most commonly occurring combination of notes fields included a Summary notes field (520) and one or more instances of field(s) 500 and/or 505. An example of records containing multiple notes fields is included in Figure 2. 
The general note field 500 was observed in over half of records collected and analyzed in this study. An average record containing this field was found to include 1.63 instances of it. This is consistent with the overall trends in using this field across different kinds of libraries. Field 500 is broadly defined as "Note that provides general information for which a specialized note field (i.e., a specific $5 \mathrm{XX}$ field) has not been defined." https://www.loc.gov/marc/bibliographic/bd500.html).

MARC 21 field 500 is traditionally used for a variety of purposes, in a catch-all note container function when a specific piece of information does not easily fit in any of the numerous (currently over 50) specialized note fields in the 5XX block of fields in MARC 21 Bibliographic Format standard https://www.loc.gov/marc/bibliographic/bd5xx.html. One common way of using this field in cataloging practice for decades is to indicate the source of the form of the title proper included in field 245 of the record: for example, when the book has no title page, the title is normally taken from its cover, and field 500 is included with the data value "Cover title." In analysis of CYAC-contributed records in this study, 162 records (almost a quarter of records containing field 500) were found to use this field for the "Cover title" statement. In 61 records representing board books, this field was found to represent the medium more specifically and provide very useful information for those selecting books for young children (e.g., "On board pages split horizontally in thirds to allow the reader to mix and match heads, torsos, and legs.", "On die-cut board pages with tabs, flaps, and fold-out pages.", "On die-cut board pages. Raised pieces on one page fit into indentions on the next.", "On die-cut, peek-though, and fold-out board pages.", "Includes textured board pages and a mirror that shows through die-cut padded cover.")

In cataloging practice for records representing books, the data value in MARC 21 field 500 is often directly taken from the resource, put in quotation marks, and the location in the resource where this wording was found - if not a tile page - is included in the field as well. In this study, this trend was observed in almost one-third of the CYAC-contributed records that contained field 500. Some typical examples of appropriate use of the field in this way included:

- 500 II\$a"Year 3"--Spine.

- 500 \I\$"Originally published in 1938 by Addison-Wesley Publishing Company"--Copyright page.

- $50011 \$ \mathrm{a} 24$ possible endings, just one path to survival!"--Page 4 of cover.

- 500 IISa"LEGO Ninjago : masters of spinjitzu"--Cover; 500 \|\$a"Magic tricks with instructions inside!"--Jacket;

- $5001 \mid \$ a " B a s e d$ on the TV series Peppa Pig created by Neville Astley and Mark Baker"--Back cover.

However, in 15 records analyzed in this study, the quoted text in this field was found to be used with the partially Latin-language legacy indicator "Title page verso". This statement had been retired at the point of transition from Anglo-American Cataloging Rules (AACR) to Resource 
Description and Access (RDA) standard in 2013, and catalogers are instructed to replace it with the English-language equivalent "Back of the title page". Being obsolete for at least 8 years now, the use of "verso" is confusing even for catalogers, let alone for the users of the school library catalogs: students, parents, and teachers.

Occasional instances of the application of field 500 when another, more specific field should be used were also observed in analysis of this dataset. Some examples include using field 500 for:

- the data value "Trilingual edition" that belongs to field 250 Edition statement,

- the data value "English translation of Japanese title, "Otsukisama wa doko itta."” part of which should have been included in field 546 Language note and another part in field 240 Uniform title,

- the data value "Translated from the Estonian" that belongs to field 546 Language note.

The table of contents note (MARC 21 field 505) is long considered and important field to provide significant value added for supporting user tasks when included in the record. In thus study, it was found in $7.12 \%$ of records. While this percentage is low, it is worth noting here that this field is not universally applicable as books for younger preschool children don't always have tables of contents. Most (71\%) of the table of contents notes observed in the records analyzed in this study used the basic level of content designation, for example:

- $50501 \$ a T h e$ story of Darth Vader -- Two sides of the Force -- Young Anakin Skywalker -- A special calling -- A new life begins -- Meet Queen Amidala -- Jedi training -Increasing frustration -- Powerful friend -- Unstoppable feelings -- Turning to the dark side -- Jedi heroes -- Are you on a path to the dark side? -- The dark side wins -- The end of Anakin -- The creation of Darth Vader -- Building Darth Vader -- Padmé's secret -- The rise of Darth Vader -- Civil war -- Rebel victory -- Imperial fleet -- Star Destroyer -Vader's revenge -- Cloud City -- Like father, like son -- Vader's choice -- The death of Darth Vader.

- $5050 \backslash \$ a A d v e n t u r e$ 58. One way or another -- Adventure 59. Something suspicious -Adventure 60. Cold hard truth.

- $5050 \mid \$ a T h e$ we-are-like-everybody-else game / Ellen Wittlinger -- Cupid's beaux / Cynthia Leitich Smith -- Partial reinforcement / Kerry Cohen -- When we were wild / Louise Hawes -- Lucky buoy / Chris Lynch -- For a moment, underground / Kekla Magoon -- Storm clouds fleeing from the wind / Zoë Marriott -- Choices / Mary Ann Rodman -- Quick changes / E.M. Kokie -- Call me! / Ron Koertge -- A crossroads / J.L. Powers -- Little wolf and the iron pin / Katy Moran -- Three-four time / Erica L. Kaufman -- We were together / Ann Angel -- A thousand words / Varian Johnson.

The enhanced level of content designation in MARC 21 field 505 table of contents is widely recognized as providing better support for information discovery. With enhanced level, as opposed to entering title of all chapters in a single instance of a subfield \$a and separating them 
from each other by double dashes, cataloger enters each chapter/section title into its own instance of individually-searchable subfield $\$$ t, and some other subfields can be used if applicable. This approach however was found to be used in less than $30 \%$ of records in the dataset. Examples included:

- $50500 \$ t$ The heliotrope fly with the suction-cup feet --\$tNothing to fear could be lurking quite near --\$tSome swell mutant ants holding hands as they danced.

- 50500 \$t Piggy's sandwich --\$tPiggy's pictures --\$tPiggy's bath --\$tPiggy's bedtime.

- $50500 \$ g$ Volume 1.\$tThe arrow --\$gvolume 2.\$tThe swarm --\$gvolume 3.\$tNew London --\$gvolume 4.\$tMovie night --\$gvolume 5.\$tThe horde --\$gvolume 6.\$tThe Lost --\$gvolume 7.\$the black city --\$gvolume 8.\$tThe final war --\$gvolume 9.\$tThe way home.

Some metadata quality issues that complicate the user tasks of identifying and obtaining information resources were observed in the application of field 505. In 4 records, this field was mistakenly used for non-table-of-contents information that belongs to either a summary note (field 520) or a general note field 500:

- $5050 \backslash \$ \mathrm{a} "$ They told each other everything ... except what matters most" -- Front cover.

- 50501 \$aIt's a big day for Dylan. He's helping the Animal Mechanics at his dad's garage. There are loads of cars and lorries to fix, and Dylan reckons he'll soon be an Expert Mechanic -- even if he does cause a bit of havoc along the way.

- $50501 \$ a A$ rollicking, rhyming Halloween romp -- in every colour! What colour is Halloween? Why, it's as green as an eerie glow, evil grin, vile brew, clammy skin, as white as cobwebs clinging, a misty trail, a skull, a spook, a face gone pale ... Children will learn their colours as they follow a cute little creature on his adventure through haunted halls, moonlit forests ... perhaps even a Halloween party! Jimmy Pickering's stylized settings and adorable monsters add a blast of colourful creepy-crawliness that will make kids giggle. Who knew that learning colours could be such spooky fun?

- $5050 \mid \$ a " A p p e a l s$ to 2nd -- 4th graders" -- Back cover -"Reading Level Grade 4" -- Back cover -"Original Title: Mordosauri in mare ... tesoro da salvare!" -- Title verso -Geronimo Stilton's ancient ancestor is back in another prehistoric adventure! A mysterious rodent has been shipwrecked on Mouse Island. He's a prehistoric pirate, and he's searching for a lost Stone Age treasure! Geronimo Stiltonoot and his family volunteer to help him on his dangerous hunt. Petrified cheese! Can they find the treasure without going extinct on the way?

As shown in Figure 1, seven additional notes fields appeared in between $0.15 \%$ and $5.67 \%$ of the records in the dataset. These include fields 546 Language Note $(5.67 \%$, e.g., "Translation of Le petit prince"), 504 Bibliography etc. note (1.45\%), 530 Additional Physical Form Available Note (also 1.45\%), 588 Source of Description, Etc. Note (0.87\%), 511 Participant or Performer Note $(0.29 \%)$, and 508 Creation/Production Credits Note (0.15\%). The Awards Note field 586 
that was observed in $2.33 \%$ of records in this dataset is probably the most important of these for supporting the needs of school library users. One record included 4 instances of it with the following data values:

586 II\$aALSC Notable Children's Book, 2019

586 IISaKirkus Prize Nominee for Young Readers' Literature, 2018

586 II\$aSchool Library Journal's Best Books, 2018

586 \\$\$Theodor Seuss Geisel Honor, 2019.

\section{Implications and Conclusions}

The high level of application of summary notes fields in CYAC-contributed WorldCat bibliographic records augmented by OCLC and institutions utilizing these records adequately supports the general user needs of juvenile readers and schoolteachers. However, important more specific needs of typical school library users are currently supported to a lesser extent. This includes the provision of currently under-utilized in the records enhanced versions of table of contents notes (field 505) for resources that have tables of content, target audience notes (field 521), and audience characteristics notes (field 385) for all resources. The types of target audience note that need particular attention from the community of catalogers creating records used by school libraries, as the most underrepresented currently are interest grade level, reading grade level, and motivation/interest level notes.

Overall, findings indicate the need for further record enrichment to better support school library user needs. At the same time, it is unclear whether the low level of application of study program note field 526 in CYAC-originated metadata records to represent reading programs names, interest levels, reading levels, and title point values is due to complexities involved in finding and including in the record this data or is merely a reflection of the proportion of books for children and young adults that are currently included in Accelerated Reader and Reading Counts programs. Further investigation is needed to clarify the finding of this study regarding application of field 526.

CYAC-contributed records analyzed in this study are limited to English-language or US-published fiction works. Future research is needed to compare the patterns of application of notes and other data elements of interest to school library users in bibliographic records representing fiction and nonfiction materials in different languages published in different countries. 


\section{References}

Beak, J. (2012). Children's perceptual cognitive factors in book selection and metadata schema:

Pilot study. Proceedings of the American Society for Information Science and Technology, 49(1), 1-10. https://doi.org/10.1002/meet.14504901071

Library of Congress. (2021). About the program: Children's and Young Adults' Cataloging

Program (CYAC). Retrieved June 22, 2021, from

https:/www.loc.gov/aba/cyac/about.html

Library of Congress. (2015). Descriptive cataloging for juvenile works. Retrieved June 22, 2021, from https://www.loc.gov/aba/cyac/descriptive_cyac.html

Library of Congress. (2012). Writing summaries. Retrieved June 22, 2021, from

https://www.loc.gov/aba/cyac/summaries.html

IFLA. (2019, December). Children's and young adults' cataloging program (CYAC). IFLA Metadata Newsletter, 5(2), 7. Retrieved June 22, 2021 from

https://www.ifla.org/files/assets/cataloguing/scatn/ifla_metadata_newsletter_december_2 019.pdf

IFLA. (2020, December). News from the Library of Congress. IFLA Metadata Newsletter, 6(2), 19-23. Retrieved June 22, 2021, from

https://www.ifla.org/files/assets/classification-and-indexing/newsletters/newsletterdecem ber2020.pdf

IFLA FRBR Review Group. (2017). IFLA Library Reference Model (LRM). Retrieved June 22, 2021, from https://www.ifla.org/files/assets/cataloguing/frbr-lrm/ifla-lrm-august-2017_rev201712.pd $\mathrm{f}$

OCLC. (2009). Online catalogs: What users and librarians want: An OCLC report. Dublin, OH. Retrieved June 22, 2021 from

https://confluence.ucop.edu/download/attachments/34668692/OCLC+report+Online+Cat alogs+What+Users+and+Librarians+Want.pdf

Taylor, A.G., \& Simpson, C.W. (1986). Accuracy of LC copy: A comparison between copy that began as CIP and other LC cataloging. Library Resources \& Technical Services, 30(4), 375-387.

Thomas, S. (1996). Quality in Bibliographic Control - history and future of cataloging in libraries; Perspectives on Quality in Libraries. Retrieved June 22, 2021, from https://ecommons.cornell.edu/bitstream/handle/1813/2669/Quality\%20in\%20Bibliograph ic\%20Control.doc

Weihs, J., \& Intner, S. (2017). Beginning Cataloging (2nd ed.). Libraries Unlimited. 